Jurnal Health Sains: p-ISSN: 2723-4339 e-ISSN: 2548-1398

Vol. 2, No. 5, Mei 2021

\title{
HUBUNGAN PERILAKU DAN FAKTOR PENYEBAB PENGGUNAAN ANTIBIOTIK TANPA RESEP DI KALANGAN MAHASISWA UNIVERSITAS TADULAKO
}

\section{Tri Randy Saputra, Amelia Rumi dan Ririen Hardani}

Universitas Tadulako Sulawesi Tengah, Indonesia

Email: threerandysaputra1999@gmail.com,amelia.rumi@gmail.com dan ririenhardani@gmail. com

\begin{tabular}{l}
\hline ARTIKEL INFO \\
\hline Tanggal diterima: 5 Mei 2021 \\
Tanggal revisi: 15 Mei 2021 \\
Tanggal yang disetujui: 25 Mei \\
2021 \\
\hline
\end{tabular}

Keywords:

antibiotics; causal factors;

students; behavior

\begin{abstract}
Behavior and causal factors affect the rate of antibiotic use without a prescription because self-medicating efforts require the extent to which students' understanding of antibiotic use is good and also correct. The purpose of this study is to find out the behavior of non-prescription antibiotic use among tadulako university students, to find out the causative factors of antibiotic use without prescription among tadulako university students, to find out the relationship of behavior and causative factors of antibiotic use without a prescription among tadulako university students and to find out what antibiotics are most consumed without a prescription among tadulako University students. This study used a descriptive method with a cross-sectional approach with 396 respondents. The sampling technique in this study, namely using purposive sampling data collection using questionnaires in Google Form. The results found that the most widely used antibiotic is amoxicillin. Behavior variables are classified as sufficient categories of (63\%). Variable causal factors fall into a sufficient category of (66\%). Variable level of causal factors that fall into the category of good assessment, namely sub-variables ease of obtaining antibiotics. When viewed by age, gender and class have sufficient knowledge. In conclusion, the results of the chisquare test obtained a value of $0.000<0.05$ which means there is a significant relationship between behavior and factors causing antibiotic use without a prescription among tadulako university students.
\end{abstract}

\begin{abstract}
ABSTRAK
Perilaku dan faktor penyebab berpengaruh terhadap tingkat penggunaan antibiotik tanpa resep karena upaya mengobati diri sendiri membutuhkan sejauh mana pemahaman mahasiswa tentang penggunaan antibiotik yang baik dan juga benar. Tujuan penelitian ini untuk mengetahui perilaku penggunaan antibiotik tanpa resep di kalangan mahasiswa Universitas Tadulako, untuk mengetahui faktor penyebab penggunaan antibiotik tanpa resep di kalangan mahasiswa Universitas Tadulako, untuk mengetahui hubungan perilaku dan faktor penyebab penggunaan antibiotik tanpa resep di
\end{abstract}

\begin{tabular}{lll}
\hline How to cite: & Saputra, Tri Randy (2021) Hubungan Perilaku dan Faktor Penyebab Penggunaan Antibiotik Tanpa \\
& $\begin{array}{l}\text { Resep di Kalangan Mahasiswa Universitas Tadulako. Jurnal Health Sains 2(5). } \\
\text { https://doi.org/10.46799/jhs.v2i5.167 }\end{array}$ & \\
E-ISSN: & $2723-6927$ \\
Published by: & Ridwan Institute
\end{tabular}


kalangan mahasiswa Universitas Tadulako dan untuk mengetahui antibiotik apa yang paling banyak dikonsumsi tanpa resep di kalangan mahasiswa Universitas tadulako. Penelitian ini menggunakan metode deskriptif dengan pendekatan cross sectional dengan jumlah responden 396 orang. Adapun teknik pengambilan sampel dalam penelitian ini, yaitu memakai purposive sampling pengambilan datanya menggunakan kuesioner di Google Form. Hasil penelitian didapatkan bahwa antibiotik paling banyak digunakan yakni amoxicillin. Variabel perilaku yaitu tergolong dalam kategori cukup yakni sebesar (63\%). Variabel faktor penyebab tergolong dalam kategori cukup yakni sebesar $(66 \%)$. Tingkat variabel faktor penyebab yang termasuk dalam kategori penilaian baik yakni sub variabel kemudahan mendapatkan antibiotik. Jika dilihat berdasarkan usia, jenis kelamin dan angkatan memiliki pengetahuan cukup. Kesimpulannya itu hasil uji chi square, didapatkan nilai $0.000<0.05$ yang

Kata Kunci: antibiotik, faktor penyebab, mahasiswa, perilaku berarti terdapat hubungan signifikasi antara perilaku dan faktor penyebab penggunaan antibiotik tanpa resep di kalangan mahasiswa Universitas Tadulako.

\section{Pendahuluan}

Antibiotik merupakan obat yang dapat mengobati dan mencegah penyakit infeksi yang disebabkan oleh bakteri (Desrini, 2015). Obat ini juga, banyak beredar di Indonesia. Kini masih banyak ditemukan perilaku yang keliru atas penggunaan antibiotik karena menganggap antibiotik adalah obat segala penyakit dan dampaknya dapat berisiko terjadinya resistensi antibiotik (KemenKes, 2016).

Peningkatan resistensi antibiotik menyulitkan dokter untuk mengobati penyakit infeksi yang banyak terjadi dikalangan masyarakat, sehingga dapat menyebabkan sakit yang berkepanjangan, disabilitas, dan kematian. Disaat tubuh sudah kebal terhadap antibiotik, maka berbagai macam prosedur medis seperti pengobatan diabetes, kemoterapi, transplantasi organ, dan operasi bisa menjadi sangat beresiko (Inayah \& Karwiky, 2020). Hal ini dapat menyebabkan pasien harus menanggung perawatan yang lama dan mahal. Krisis resistensi bakteri terhadap bakteri utamanya disebabkan oleh penggunaan antibiotik yang tidak tepat dan berlebihan, disamping itu juga penemuan antibiotik jenis baru memerlukan waktu yang cukup lama (Pusporini, 2016).

Berdasarkan hasil penelitian (Kurniawati \& Savitri, 2019), dengan kusioner yang berisi beberapa pertanyaan bahwa antibiotik harus dibeli dengan resep dokter, terdapat hasil sebanyak $39 \%$ responden selalu membeli atau mendapatkan obat antibiotik menggunakan resep dan $61 \%$ tidak membeli antibiotik dengan menggunakan resep dokter, dimana terlihat bahwa masih banyak kekeliruan di masyarakat tentang antibiotik harus selalu dibeli dengan resep, padahal antibotik merupakan golongan obat keras dimana harus dibeli dengan resep dokter (KemenKes, 2016).

Berdasarkan (Riskesdas, 2013), ditemukan sebanyak $86 \%$ rumah tangga atau kartu keluarga di seluruh provinsi di Indonesia yang menyimpan dan swamedikasi obat antibiotik. Penjualan antibiotik yang dilakukan secara bebas di apotek, kios mempermudah masyarakat mendapatkannya dengan mudah, bahkan ada yang menyimpan 
obat dan juga antibiotik cadangan di rumah masing-masing, hingga meminta tolong ke dokter agar dituliskan resep antibiotik. Dan itu semua bisa menyebabkan sikap buruk seperti terjadinya resistensi antibiotik (KemenKes, 2016).

Pengobatan infeksi pun berkembang luas di masyarakat (Organization, 2013). Perilaku ini menjadi masalah kesehatan yang bahaya dan penting di perbaiki di seluruh masyarakat. Menurut (Riskesdas, 2013), rumah tangga yang menyimpan antibiotik untuk pengobatan diri sendiri yaitu terdapat 90,2\%. dikota Yogyakarta pun yang menggunakan antibiotik tanpa resep sebesar 7,3\% (Widayati et al., 2011). Hal tersebut merupakan keprihatinan mendalam didunia kesehatan karena bisa menyebabkan pengaruh negatif bagi masyarakat. Tercatat di seluruh dunia, resistensi antimikroba membunuh sekitar 700.000 jiwa dalam setiap tahunnya, termasuk 230.000 jiwa yang resisten terhadap obat Tubercolusis (Organization, 2019). Angka kematian yang di sebabkan resistensi antimikroba di Indonesia sampai tahun 2014 kurang lebih mencapai 800.000 per tahun. Dengan semakin pesatnya perkembangan dan penyebaran infeksi bakteri bisa-bisa kedepannya angka kematian akibat resistensi lebih besar (KemenKes, 2016).

Menurut (Djawaria \& Maker, 2018), di perlukan intervensi bagi tenaga medis yang manjur dan mujarab agar bisa memperbaiki pola dan perilaku penggunaan antibiotik. Untuk menghasilkan intervensi tersebut yang manjur dan mujarab sangat perlu dilakukan penggalian hal-hal yang mempengaruhi penggunaan obat antibiotik tanpa resep di apotek. Sampai saat ini belum di temukan bukti valid dan penelitian terpublikasi yang menetapkan faktor utamanya yang menyebabkan masyarakat sampai mahasiswa menggunakan obat antibiotik tanpa resep dokter. Tanpa data tersebut, dicemaskannya akan ditemukan metode intervensi yang tidak tepat sasaran sampai menyebabkan timbulnya masalah baru. Tujuan peneliti dapat melihat perilakunya dan menentukan faktor utama yang dapat mempengaruhi adanya penggunaan antibiotik tanpa resep dokter di kalangan mahasiswa.

Berdasarkan penjelasan tadi, perlunya untuk melakukan penelitian mengenai penggunaan antibiotik dengan menggunakan resep di kalangan mahasiswa dimana peneliti mengharapkan penggunaan antibiotik yaitu mahasiswa bisa paham lebih baik. Oleh karena itu sebagai peneliti bisa mengetahui sejauh mana pemahaman masyarakat khususnya mahasiswa tentang penggunaan antibiotik dan Data yang akan diperoleh masih dalam lingkup mahasiswa Universitas Tadulako. Hal ini yang melatarbelakangi untuk dilakukan penelitian tentang Hubungan Perilaku dan Faktor Penyebab Penggunaan Antibiotik Tanpa Resep di Kalangan Mahasiswa Universitas Tadulako.

\section{Metode Penelitian}

Penelitian ini sudah dinyatakan sesuai dengan prinsip-prinsip etika penelitian oleh Komite Etik Penelitian Fakultas Kedokteran Universitas Tadulako dengan dikeluarkannya Surat Pernyataan Komite Etik dengan nomor: 104/UN 28.1.30/KL/2021.

Penelitian ini merupakan penelitian non eksperimental (observasional) dan bersifat cross-sectional, dengan rancangan penelitian metode survei serta kuesioner sebagai instrument penelitian dalam pengambilan data untuk melihat persentasi hubungan perilaku dan faktor penyebab penggunaan antibiotik tanpa resep di kalangan mahasiswa Universitas Tadulako.

Penelitian ini dilakukan pada bulan Desember 2020 bertempat di kampus Universitas Tadulako Jl. Soekarno Hatta, KM. 9, Tondo, Mantikulore, Kota Palu, Sulawesi Tengah. Teknik pengambilan sampel purposive sampling yaitu semua mahasiswa yang memenuhi kriteria inklusi dan eksklusi. 
Tri Randy Saputra, Amelia Rumi dan Ririen Hardani

Validitas adalah suatu indeks yang bertujuan untuk menguji sampai mana suatu kebenaran kuisioner dalam usaha soal validitas merupakan aspek yang sangat penting. Uji Validitas ini memakai aplikasi SPSS 21. Suatu kuesioner dinyatakan valid jika nilainya rhitung > rtabel. Reliabilitas sangat penting dilakukan untuk mengukur suatu konsistensi dan kestabilan responden untuk menjawab pertanyaan dalam kuesioner dari setiap variabel yang ada. Uji reliabilitas dapat dilakukan dengan ini memakai aplikasi SPSS 21. Untuk kriteria uji reliabilitas dari suatu variabel yang bisa dikatakan baik jika memiliki nilai rhitung > rtabel.

\section{Hasil dan Pembahasan}

\section{a. Uji Validitas Kuesioner Perilaku}

\begin{tabular}{lccl}
\hline Pertanyaan & r-hitung & r-tabel & Keterangan \\
\hline P1 & 0,775 & 0,361 & Valid \\
\hline P2 & 0,368 & 0,361 & Valid \\
\hline P3 & 0,701 & 0,361 & Valid \\
\hline P4 & 0,588 & 0,361 & Valid \\
\hline P5 & 0,563 & 0,361 & Valid \\
\hline P6 & 0,647 & 0,361 & Valid \\
\hline P7 & $\mathbf{0 , 0 9 7}$ & 0,361 & Tidak Valid \\
\hline P8 & 0,775 & 0,361 & Valid \\
\hline P9 & 0,441 & 0,361 & Valid \\
\hline P10 & 0,588 & 0,361 & Valid \\
\hline P11 & 0,563 & 0,361 & Valid \\
\hline P12 & 0,647 & 0,361 & Valid \\
\hline P13 & 0,775 & 0,361 & Valid \\
\hline P14 & 0,393 & 0,361 & Valid \\
\hline P15 & $\mathbf{0 , 0 9 5}$ & 0,361 & Tidak Valid \\
\hline P16 & 0,701 & 0,361 & Valid \\
\hline P17 & 0,775 & 0,361 & Valid \\
\hline P18 & 0,701 & 0,361 & Valid \\
\hline
\end{tabular}

\section{b. Uji Validitas Kuesioner Faktor} Penyebab

\begin{tabular}{llrl}
\hline Pertanyaan & r-hitung & r-tabel & Keterangan \\
\hline P1 & 0,419 & 0,361 & Valid \\
\hline P2 & 0,488 & 0,361 & Valid \\
\hline P3 & 0,399 & 0,361 & Valid \\
\hline P4 & 0,488 & 0,361 & Valid \\
\hline P5 & 0,401 & 0,361 & Valid \\
\hline P6 & 0,560 & 0,361 & Valid \\
\hline P7 & 0,378 & 0,361 & Tidak Valid \\
\hline P8 & 0,560 & 0,361 & Valid \\
\hline P9 & 0,365 & 0,361 & Valid \\
\hline P10 & 0,334 & 0,361 & Valid \\
\hline P11 & 0,395 & 0,361 & Valid \\
\hline P12 & 0,583 & 0,361 & Valid \\
\hline P13 & 0,508 & 0,361 & Valid \\
\hline P14 & 0,475 & 0,361 & Valid \\
\hline P15 & 0,306 & 0,361 & Tidak Valid \\
\hline P16 & 0,454 & 0,361 & Valid \\
\hline
\end{tabular}

\begin{tabular}{cccc}
\hline P17 & 0,453 & 0,361 & Valid \\
\hline P18 & 0,448 & 0,361 & Valid \\
\hline & Pengujian validitas dilakukan untuk
\end{tabular}
menentukan nilai korelasi pearson (rhitung) dengan total 36 pertanyaan dan ada 4 pertanyaan yang tidak valid karena kebenaran 4 pertanyaan itu ambigu atau tidak jelas. Tujuan validitas untuk mengetahui cara untuk membuktikan suatu kebenaran dari pertanyaan dengan isi dan materi yang jelas. Ketika rhitung ditemukan lebih besar dari rtabel $(0,361)$ maka pertanyaan tersebut dinyatakan valid (Herlina, 2019).

\section{c. Uji Reliablitas Perilaku}

\begin{tabular}{lc}
\hline Cronbach's Alpha & N of Items \\
\hline 0.844 & 18 \\
\hline
\end{tabular}

d. Uji Reliablitas Faktor penyebab

\begin{tabular}{ll}
\hline Cronbach's Alpha & N of Items \\
\hline 0.712 & 18 \\
\hline
\end{tabular}

Menurut (Budiman-Mak et al., 2013) Reliabilitas adalah suatu alat pengukuran yang dapat dipercaya sebagai tingkat konsistensi atau indeks yang menunjukkan sampai mana suatu tes yang di ukur pada pernyataan dan pertanyaan yang sudah valid. Metode pengambilan keputusan untuk uji reliabilitas memakai batasan 0,6. Dari hasil yang didapatkan pada uji reliabilitas nilai Cronbach's Alpha pada kuesioner perilaku yaitu sebesar 0,844 kriteria reliabilitas tinggi dan pada kuesioner faktor penyebab yaitu sebesar 0,712 kriteria reliabilitas tinggi yang berarti kedua kuesioner tersebut dikatakan reliable jika didapatkan nilai Cronbach's alpha yang lebih besar dari 0,6 (Priyatmoko, 2015). 
Hubungan Perilaku dan Faktor Penyebab Penggunaan Antibiotik Tanpa Resep di Kalangan Mahasiswa Universitas Tadulako

\section{e. Sampel}

1. Jumlah responden mahasiswa

Universitas Tadulako

\begin{tabular}{ll}
$\begin{array}{l}\text { Responden mahasiswa } \\
\text { Universitas Tadulako } \\
\text { angkatan 2017, 2018 } \\
\text { dan 2019 }\end{array}$ & Jumlah responden \\
\cline { 1 - 2 } Memenuhi Kriteria & 396 \\
\hline Total & 396 \\
\hline
\end{tabular}

Dari hasil pengumpulan data yang dilakukan melalui google form pada mahasiswa Universitas Tadulako angkatan 2017, 2018 dan 2019 didapatkan responden berjumlah 396 orang, responden dari angkatan 2017 berjumlah 182 orang, angkatan 2018 berjumlah 125 orang dan angkatan 2019 berjumlah 89 orang.

f. Dekskripsi Responden Mahasiswa Universitas Tadulako 2017, 2018, dan 2019

\begin{tabular}{|c|c|c|c|}
\hline Variabel & Kategori & $\begin{array}{c}\text { Jumlah } \\
\text { Respondn } \\
(\mathrm{n}=396)\end{array}$ & $\begin{array}{c}\text { Persentase } \\
(\%)\end{array}$ \\
\hline & $\begin{array}{l}17-20 \\
\text { tahun } \\
\end{array}$ & 206 & 52,02 \\
\hline \multirow[t]{3}{*}{ Usia } & $\begin{array}{l}21-23 \\
\text { tahun }\end{array}$ & 189 & 47,73 \\
\hline & tahun & 1 & 0,25 \\
\hline & Total & 396 & 100 \\
\hline \multirow[t]{4}{*}{ Jenis kelamin } & Laki-laki & 124 & 31.31 \\
\hline & Perempuan & 272 & 68.69 \\
\hline & Total & 396 & 100 \\
\hline & $\begin{array}{l}\text { Tahun } \\
2017\end{array}$ & 182 & 45.96 \\
\hline \multirow[t]{3}{*}{ Angkatan } & $\begin{array}{l}\text { Tahun } \\
2018\end{array}$ & 125 & 31,57 \\
\hline & $\begin{array}{l}\text { Tahun } \\
2019\end{array}$ & 89 & 22,47 \\
\hline & Total & 396 & 100 \\
\hline
\end{tabular}

Pada uraian ini akan dijelaskan karakteristik pada 396 responden berupa usia, jenis kelamin, dan angkatan. Pada tabel 4.2 dijelaskan bahwa berdasarkan kategori usia responden 17-20 sebanyak 206 orang $(52,02 \%)$, usia 21-23 sebanyak 189 orang $(47,73 \%)$, dan usia 24 sebanyak 1 orang $(0,25 \%)$. Berdasarkan kategori jenis kelamin, responden laki-laki sebanyak 124 orang $(31,31 \%)$, sedangkan responden perempuan sebanyak 272 orang $(68,69 \%)$. Berdasarkan kategori angkatan, responden angkatan 2017 sebanyak 182 orang (45,96\%), angkatan 2018 sebanyak 125 orang $(31,57 \%)$, dan angkatan 2019 sebanyak 89 orang $(22,47 \%)$.

g. Hasil Kuisioner Responden Tentang Perilaku Dan Faktor Penyebab

\begin{tabular}{|c|c|c|c|}
\hline \multicolumn{3}{|c|}{ Tingkat Hubungan } & Total \\
\hline Variabel & Iya & Tidak & Jumlah \\
\hline & $(\%)$ & $(\%)$ & $(\%)$ \\
\hline Perilaku & $63,08 \%$ & $36,20 \%$ & $396(100 \%)$ \\
\hline $\begin{array}{l}\text { Faktor } \\
\text { penyebab }\end{array}$ & $66,62 \%$ & $33,38 \%$ & \\
\hline
\end{tabular}

Berdasarkan tabel 4.4 terdapat 2 variabel yang mewakili 32 pertanyaan yang telah disebarkan ke responden. Pertanyaan pada variabel mengenai perilaku dan faktor penyebab bertujuan untuk mengetahui apakah responden telah memahami tentang mengkonsumsi antibiotik tanpa resep dokter.

\section{h. Distribusi frekuensi mahasiswa} Universitas Tadulako tentang perilaku dan faktor penyebab

\begin{tabular}{|c|c|c|c|}
\hline \multicolumn{3}{|c|}{ Jumlah dan presentase responden } & Total \\
\hline Variabel & Baik & Cukup & Kurang \\
\hline & $(\%)$ & $(\%)$ & $(\%)$ \\
\hline Perilaku & 80 & 231 & 85 \\
\hline & $20,21 \%$ & $58,33 \%$ & $21,46 \%$ \\
\hline Faktor & 158 & 182 & 56 \\
\hline penyebab & $39,90 \%$ & $45,96 \%$ & $14,14 \%$ \\
\hline
\end{tabular}

Tabel tersebut merupakan hasil responden berdasarkan indikator kuesioner hubungan mahasiswa Universitas Tadulako tentang penggunaan antibiotik tanpa resep dokter di kalangan mahasiswa. Indikator terdiri dari 2 pertanyaan tentang penggunaan antibiotik tanpa resep di kalangan mahasiswa yang dimana banyak mahasiswa yang cukup paham tentang perilaku penggunaan antibiotik dilihat dari hasil jawaban mahasiswa sebanyak (58.33\%) yang 
masuk dalam kategori cukup baik hal ini dikarenakan perilaku penggunaan antibiotik tanpa resep merupakan pengetahuan yang umum dan dialami oleh mahasiswa dan sebagian besar mahasiswa memahami perilaku tentang penggunaan antibiotik tanpa resep dokter. Hal ini sama dengan penelitian yang dilakukan (Djawaria \& Maker, 2018) tentang hasil hubungan tersebut menjelaskan bahwa faktor yang sangat mempengaruhi perilaku mendapatkan antibiotik tanpa resep dokter ialah halhal yang mendorong untuk melakukannya seperti akses untuk memperoleh antibiotik tanpa resep.

i. Distribusi frekuensi faktor penyebab di kalangan mahasiswa Universitas Tadulako tentang penggunaan antibiotik tanpa resep

\begin{tabular}{cccc}
\hline \multirow{2}{*}{ Indikator } & \multicolumn{3}{c}{ Jumlah dan } \\
& \multicolumn{2}{c}{ presentase responden } & \\
\cline { 2 - 3 } & Baik & Cukup & Kurang \\
\hline Pengetahuan & 71 & 123 & 202 \\
& $17.93 \%$ & $31.06 \%$ & $51,01 \%$ \\
\hline Pembelian & 220 & 99 & 77 \\
& $55,56 \%$ & $25.00 \%$ & $19.44 \%$ \\
\hline Kemudahan & 235 & 102 & 59 \\
Mendapatka & $59.34 \%$ & $25.76 \%$ & $14.90 \%$ \\
n Antibiotik & & & \\
\hline
\end{tabular}

$\begin{array}{ccr}\text { Berdasarkan tabel } & \text { tersebut } \\ \text { merupakan hasil responden }\end{array}$
berdasarkan indikator kuesioner faktor penyebab mahasiswa Universitas Tadulako tentang penggunaan antibiotik tanpa resep. Terdapat beberapa faktor penyebab mahasiswa Universitas Tadulako dalam penggunaan antibiotik tanpa resep. Yaitu seperti sub faktor pembelian 77 orang (19.44\%), faktor kemudahan mendapatkan antibiotik 59 orang (14.90\%), dan faktor pengetahuan yang paling besar yaitu berjumlah 202 orang (51.01\%). Terdapat faktor pengetahuan yang paling besar berpengaruh sebagai faktor penyebab penggunaan antibiotik tanpa resep di kalangan mahasiswa Universitas Tadulako. Karena kurangnya edukasi dalam pendidikan kesehatan itu merupakan proses dalam terjadinya perubahan kemampuan bahkan sikap yang tidak diinginkan pada subjek belajar dengan hasil yang diharapkan adalah kemampuan sebagai perubahan perilaku dari sasaran didik. kegiatan edukasi dilaksanakan dengan tujuan meningkatkan pengetahuan, agar dapat menggunakan antibiotik secara bijak dan kurangnya pengetahuan masyarakat tentang obat sebagai pencegahnya dan gaya hidup yang tidak sehat sehingga masyarakat memerlukan edukasi farmasi untuk mengenal dan mencegah penyakit dengan mulai merubah gaya hidup (Rahmawaty et al., 2018).

j. Hubungan Perilaku dan Faktor Penyebab Penggunaan Antibiotik Tanpa Resep Dokter di Kalangan Mahasiswa Universitas Tadulako

\begin{tabular}{llll}
\hline Value & & Df & $\begin{array}{l}\text { Asymp. Sig (2 } \\
\text { sided) }\end{array}$ \\
\hline $\begin{array}{l}\text { Pearson } \\
\text { Chi-Square }\end{array}$ & 214,355 & 4 & 0,000 \\
\hline $\begin{array}{l}\text { N of Valid } \\
\text { Cases }\end{array}$ & 396 & & \\
\hline
\end{tabular}

Berdasarkan tabel hasil uji statistik Chi Square pada pengujian hubungan perilaku dengan faktor penyebab penggunaan antibiotik tanpa resep didapatkan nilai Chi Square hitung (Nilai hasil uji chi square) sebesar 214.355 dengan nilai signifikansi sebesar 0,000, maka jika dilihat dari nilai signifikasi, nilai 0.000 $<0.05$ sehingga disimpulkan menolak HO ditolak sehingga terdapat hubungan antara perilaku dan faktor penyebab penggunaan antibiotik, sama halnya penelitian yang pernah dilakukan (Djawaria \& Maker, 2018) menunjukan bahwa hasil penelitiannya disimpulkan bahwa menggunakan antibiotik yang dibeli sembarangan tanpa resep dokter 
Hubungan Perilaku dan Faktor Penyebab Penggunaan Antibiotik Tanpa Resep di Kalangan Mahasiswa Universitas Tadulako

di wilayah Surabaya dan sekitarnya kebanyakan dilakukan oleh masyarakat dari umur 15 tahun untuk mengobati gejala yang disebabkan oleh patogen non-bakteri. peristiwa yang sangat mempengaruhi perilaku masyarakat untuk mendapatkan antibiotik tanpa resep dokter dalam penelitian ini termasuk kemudahan akses untuk memperoleh antibiotik di apotek. Hasil dari penelitian ini menujukan bahwa ada hubungan antara perilaku dan faktor penyebab penggunaan antibiotik tanpa resep di kalangan mahasiswa Universitas Tadulako.

\section{Kesimpulan}

Pertama Terdapat perilaku mahasiswa Universitas Tadulako dalam penggunaan antibiotik tanpa resep, mayoritas tergolong memiliki perilaku yang cukup baik dalam mengkonsumsi antibiotik.

Kedua Terdapat beberapa faktor penyebab mahasiswa Universitas Tadulako dalam penggunaan antibiotik tanpa resep. Yaitu seperti sub faktor pembelian 77 orang (19.44\%), faktor kemudahan mendapatkan antibiotik 59 orang (14.90\%), dan faktor pengetahuan yang paling besar yaitu berjumlah 202 orang $(51.01 \%)$. Terdapat faktor pengetahuan yang paling besar berpengaruh sebagai faktor penyebab penggunaan antibiotik tanpa resep di kalangan mahasiswa Universitas Tadulako.

Ketiga Terdapat hubungan signifikasi antara perilaku dan faktor penyebab penggunaan antibiotik tanpa resep di kalangan mahasiswa Universitas Tadulako.

Keempat Diketahui bahwa dari 396 responden didapatkan bahwa antibiotik amoxicillin paling banyak dikonsumsi tanpa menggunakan resep dengan jumlah 271 orang $(68,43 \%)$.

\section{BIBLIOGRAFI}

Budiman-Mak, E., Conrad, K. J., Mazza, J., \& Stuck, R. M. (2013). A Review Of The Foot Function Index And The Foot Function Index-Revised. Journal of Foot And Ankle Research, 6(1), 1-37. Google Scholar

Desrini, S. (2015). Resistensi Antibiotik, Akankah Dapat Dikendalikan? Jurnal Kedokteran Dan Kesehatan Indonesia, 6(4). Google Scholar

Djawaria, F. P. A., \& Maker, L. P. I. I. (2018). Cardiac Myxoma. Medicina, 49(2), 236-240. Google Scholar

Herlina, V. (2019). Panduan Praktis Mengolah Data Kuesioner Menggunakan Spss. Elex Media Komputindo. Google Scholar

Inayah, D. R. N., \& Karwiky, D. R. G. (2020). Kiat Sehat Dengan Dan Tanpa Obat. Mizan Qanita. Google Scholar

Kemenkes, R. I. (2016). Buku Kesehatan Ibu Dan Anak. In Kementrian Kesehat Ri Dan Jica Jakarta. Google Scholar

Kurniawati, D. A., \& Savitri, H. (2019). Awareness Level Analysis Of Indonesian Consumers Toward Halal Products. Journal Of Islamic Marketing. Google Scholar

Organization, W. H. (2013). Transforming And Scaling Up Health Professionals' Education And Training: World Health Organization Guidelines 2013. World Health Organization. Google Scholar

Organization, W. H. (2019). Global Status Report On Alcohol And Health 2018. World Health Organization. Google Scholar

Priyatmoko, S. A. (2015). Pengaruh Lifestyle Dan Social Influence Terhadap Keputusan Pembelian (Studi Pada 
Tri Randy Saputra, Amelia Rumi dan Ririen Hardani

Pengguna Sepatu Futsal Merek Specs). Manajemen-Fe. Google Scholar

Pusporini, A. (2016). Biodiversitas Bakteri Pada Tanah Tercemar Air Lindi Tempat Pemrosesan Akhir (Tpa) Supit Urang Kota Malang. Universitas Brawijaya. Google Scholar

Riskesdas. (2013). Riskesdas 2013. In Jakarta Kementeri Kesehat Ri (Vol. 6). Google Scholar

Widayati, A., Suryawati, S., De Crespigny, C., \& Hiller, J. E. (2011). Self Medication With Antibiotics In Yogyakarta City Indonesia: A Cross Sectional Population-Based Survey. Bmc Research Notes, 4(1), 1-8. Google Scholar

(2018). Edukasi Kesehatan Farmasi Penyakit Rematik Di Desa Nganguk Kota Kudus. Jurnal Pengabdian Kesehatan. Google Scholar

\section{Copyright holder:}

Tri Randy Saputra, Amelia Rumi dan Ririen Hardani (2021)

First publication right:

Jurnal Health Sains

This article is licensed under:

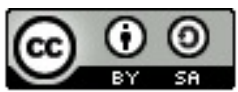

